\title{
EDUCAÇÃO PARA SUSTENTABILIDADE ULTRAPASSANDO FRONTEIRAS: EXPERIÊNCIA ENTRE ESCOLA E UNIVERSIDADE ${ }^{1}$
}

\begin{abstract}
Sandra Lilian Silveira Grohe ${ }^{2}$
RESUMO: O presente artigo tem por objetivo relatar a experiência vivida entre a Escola Municipal de EMEF Santa Marta, localizada em São Leopoldo, Rio Grande do Sul e a Universidade de Michigan, localizada em Ann Arbor, Estados Unidos. Essa experiência teve início, no ano de 2013, com a participação da escola na IV Conferência Nacional Infanto-juvenil pelo Meio Ambiente. Esse movimento foi muito significativo, pois a escola passou a se destacar como promotora da educação para a sustentabilidade. Integrando currículo, gestão e edificações em prol da sustentabilidade socioambiental, aos poucos foi modificando seu modo de ser e, consequentemente, seu entorno foi afetado. Um dos desdobramentos significativos desse movimento foi a parceria realizada com a Universidade de Michigan e a construção do projeto denominado "Together We Make Santa Marta Home". Ele culminou em um importante documento com recomendações para o desenvolvimento de espaços públicos e programas de educação para a sustentabilidade.
\end{abstract}

Palavras-chave: Sustentabilidade. Escola. Universidade.

\section{EDUCATION FOR SUSTAINABILITY OUTSIDE OF BORDERS: EXPERIENCE BETWEEN SCHOOL AND UNIVERSITY}

ABSTRACT: The purpose of this article is to describe the experience lived between the Municipal School of EMEF Santa Marta, located in São Leopoldo, Rio Grande do Sul and the University of Michigan, located in Ann Arbor, United States. This experience began in the year 2013 with the participation of the school in the IV Juvenile Child National Conference for the Environment. This movement was very significant because the school started to stand out as producer of education for sustainability. Integrating curriculum, management and buildings for the socioenvironmental sustainability, gradually modified its way of being and consequently its environment was affected. One of the significant outspreads of this movement was the partnership with Michigan University and the construction of the project "Together We Make Santa Marta our Home". This culminated in an important document with recommendations for the development of public spaces and education programs for sustainability, in which it was put into practice

\footnotetext{
1 Resumo expandido publicado nos anais do V Seminário da Associação Nacional de Políticas e Administração da Educação (ANPAE) Regional Sul em 2018.

2 Mestre em Educação. Doutoranda em Educação pela Universidade do Rio dos Sinos. (Unisinos). São Leopoldo - RS/Brasil. Professora da Universidade La Salle. Canoas - RS/Brasil. E-mail: sandragrohe@gmail.com
}

Argumentos Pró-Educação, Pouso Alegre, v. 4, n. 12, p. 1288- 1304. set. - dez., 2019

ISSN: 2448-2803 http://dx.doi.org/10.24280/ape.v4i12.467 
through the engagement of several people and follow up, going beyond expected. Keywords: Sustainability. School. University.

\section{EDUCACIÓN PARA SOSTENIBILIDAD ULTRAPASANDO FRONTERAS: EXPERIENCIA ENTRE ESCUELA Y UNIVERSIDAD}

RESUMEN: El presente artículo tiene por objetivo relatar la experiencia vivida entre la Escuela Municipal de EMEF Santa Marta, ubicada en São Leopoldo, Rio Grande do Sul y la Universidad de Michigan, ubicada en Ann Arbor, Estados Unidos. Esa experiencia comenzó en el año 2013 con la participación de la escuela en la IV Conferencia Nacional Infantojuvenil por el Medio Ambiente. Ese movimiento fue muy significativo, pues la escuela pasó a destacarse como promotora de la educación para la sostenibilidad. Integrando currículum, gestión y edificaciones en favor de la sostenibilidad socioambiental, poco a poco fue modificando su modo de ser y, consecuentemente, su entorno fue afectado. Uno de los desdoblamientos significativos de ese movimiento fue la asociación realizada con la Universidad de Michigan y la construcción del proyecto denominado Together We Make Santa Marta Home. Él culminó en un importante documento con recomendaciones para el desarrollo de espacios públicos y programas de educación para la sostenibilidad en la Vila Santa Marta, en la cual fue puesto en práctica a través del compromiso de diversas personas y seguimientos, yendo más allá de lo esperado.

Palabras clave: Sostenibilidad. Escuela. Universidad.

A partir do Fórum Brasileiro de ONGs e Movimentos Sociais e o Desenvolvimento (FBOMS), realizado concomitante à Conferência das Nações Unidas sobre Meio Ambiente e Desenvolvimento (ECO92), o conceito de desenvolvimento sustentável vem sendo questionado. Entre as críticas, focaliza-se a defesa da exploração dos recursos naturais e dos investimentos lucrativos a favor das necessidades e pretensões humanas. Durante a ECO92, o que se buscou foi o distanciamento desse posicionamento, demarcando uma nova preocupação com a sustentabilidade da sociedade (SCOTTO; CARVALHO; GUIMARÃES, 2009).

Nesse sentido, foi criado o Tratado de Educação Ambiental para Sociedades Sustentáveis e Responsabilidade Global (TEASS), no qual o conceito de desenvolvimento sustentável foi deslocado para o conceito de sociedade justa e ecologicamente equilibrada. A educação ambiental passou a ser considerada como o "processo de aprendizagem permanente, baseado no respeito a todas as formas de vida, contribuindo para a transformação humana, social e para a preservação ecológica" (FÓRUM INTERNACIONAL DE ORGANIZAÇÕES NÃO-GOVERNAMENTAIS E MOVIMENTOS SOCIAIS, 1992).

Argumentos Pró-Educação, Pouso Alegre, v. 4, n. 12, p. 1288- 1304. set. - dez., 2019

ISSN: 2448-2803 http://dx.doi.org/10.24280/ape.v4i12.467 
A partir do TEASS e de outros documentos direcionados à educação para a sustentabilidade, foi instituído pelo governo federal, no ano de 2004, o Programa Nacional de Educação Ambiental -ProNEA ${ }^{3}$ no qual o conceito de sociedades sustentáveis,

inclui uma visão transformadora, apoiada na diversidade de buscas e soluções para a construção simultânea e coletiva das sustentabilidades ambiental, social, econômica, política e ética. Diferente do desenvolvimento sustentável, um conceito datado, que se limita à dimensão do crescimento econômico como balizador da sustentabilidade, sem criticidade e com manutenção do status quo (HENRIQUES et al., 2007, p. 29; grifos dos autores).

Desde então, outros documentos foram construídos, fortalecendo este posicionamento, dentre eles, a Política Nacional de Educação Ambiental - PNEA (Lei Federal no 9.795/1999), Diretrizes Curriculares Nacionais para a Educação Ambiental (DCNEA) e Programa Nacional Escolas Sustentáveis (PNES). Fundamentada neles e em outros documentos que tratam da educação para a sustentabilidade, a Escola Municipal de Ensino Fundamental (EMEF) Santa Marta, localizada no Município de São Leopoldo - RS, ao participar da IV Conferência Nacional Infantojuvenil pelo Meio Ambiente - CNIJMA (MEC, 2013) ${ }^{4}$, no ano de 2013, elaborou um projeto de ação voltado aos problemas socioambientais encontrados na escola e na comunidade Santa Marta.

Conforme o Art. 21 da Resolução № 2, de 15 de junho de $2012^{5}$, as instituições educacionais, com o apoio dos sistemas de ensino, devem constituir-se "em espaços educadores sustentáveis, com a intencionalidade de educar para a sustentabilidade socioambiental de suas comunidades, integrando currículos, gestão e edificações em relação equilibrada com o meio ambiente, tornando-se referência para seu território". Nessa direção, seguindo as orientações trazidas no livreto "Vamos Cuidar do Brasil com Escolas Sustentáveis" (BRASIL, 2012), foram organizados três encontros com a comunidade escolar com o intuito de proporcionar, por meio de um espaço aberto e democrático, discussões sobre os problemas locais.

Coletivamente, escola e comunidade criaram uma Comissão de Meio Ambiente e

3 O ProNEA foi instituído em 1999 e publicado em 2005. A primeira versão tinha a sigla toda em maiúsculo, PRONEA. A segunda edição, em 2014, passou a ser denominada ProNEA, assim como a terceira, finalizada em 2005.

4 Essa conferência, fundamentada em políticas de educação para a sustentabilidade, ocorre desde o ano de 2003.

5 Resolução CNE/CP 2/2012. Diário Oficial da União, Brasília, 18 de junho de 2012 - Seção 1 - p. 70.

Argumentos Pró-Educação, Pouso Alegre, v. 4, n. 12, p. 1288- 1304. set. - dez., 2019

ISSN: 2448-2803 http://dx.doi.org/10.24280/ape.v4i12.467 
Qualidade de Vida (COM-VIDA) ${ }^{6}$ e o projeto de ação denominado "Água Viva", dando prioridade aos problemas encontrados no bairro Arroio da Manteiga que passa pela Vila Santa Marta. O objetivo do projeto foi o de "sensibilizar a comunidade local para os perigos e consequências de se conviver próximo aos locais com água contaminada e poluída, assim como alertar para a responsabilidade que cada um tem com o arroio e o lugar onde vivem" (GROHE, 2015).

O projeto foi, aos poucos, se fortalecendo, principalmente quando recebeu o apoio das autoridades locais. A COM-VIDA, juntamente com a Associação de Moradores da Vila Santa Marta, Secretaria Municipal de Educação, Secretaria do Meio Ambiente, comércio e universidade local, passou a protagonizar ações conjuntas por meio da criação do Movimento Bairro Melhor - MBM. ${ }^{7}$ A COM-VIDA da EMEF Santa Marta foi identificada como um grupo mobilizador de mudanças significativas na comunidade. Esses desdobramentos foram se configurando em outros modos de ver e ser da escola.

Muitas foram as parcerias estabelecidas. Um destaque foi a experiência vivenciada junto à Universidade de Michigan. No ano de 2014, os alunos e professores do curso de Mestrado em Planejamento Urbano da Universidade de Michigan buscaram no Brasil por um projeto que desenvolvesse ações em prol da comunidade local. A intenção da Universidade de Michigan era a de construir um documento que contribuísse e ampliasse o trabalho já realizado na escola e comunidade. Ao conhecerem a COM-VIDA da EMEF Santa Marta e o projeto “Água Viva”, entraram em contato com a escola e firmaram parceria.

No mês de março de 2015, dez estudantes e dois professores passaram dez dias imersos na comunidade Santa Marta com o objetivo de conhecer a realidade e elaborar um projeto de ação. O propósito era o de ampliar e dar continuidade às ações realizadas pela COM-VIDA $^{8}$, produzir recomendações para o desenvolvimento de espaços públicos e

\footnotetext{
6 "A COM-VIDA é uma instância de participação na qual diversos atores da escola estarão representados em um processo democrático e participativo de construção da agenda ambiental escolar. Ela possibilita o debate sobre questões socioambientais, relacionando-as com os demais temas transversais, com a qualidade de vida, com os direitos humanos e com a prevenção de riscos e emergências ambientais". Disponível em: http://conferenciainfanto.mec.gov.br/images/pdf/passo_passo_vcnijma_11112017.pdf. Acesso em: 06 fev. 2018.

7 O objetivo do MBM está disponível em: http://escolasantamartasaoleopoldo.blogspot.com.br/2017/03/objetivo-domovimento-bairro-melhor-mbm.html. Acesso em: 05 jul. 2018.

8 A Com-Vida já havia produzido sua própria análise em relação ao descarte de lixo na comunidade por meio de entrevistas com moradores de 72 domicílios e distribuído panfletos informativos com o objetivo de promover a consciência ambiental e a importância de práticas sustentáveis de gestão do lixo.
}

Argumentos Pró-Educação, Pouso Alegre, v. 4, n. 12, p. 1288- 1304. set. - dez., 2019

ISSN: 2448-2803 http://dx.doi.org/10.24280/ape.v4i12.467 
programas de educação ambiental que promovessem o protagonismo ambiental, a apropriação comunitária, o aprimoramento da infraestrutura e fortalecesse a identidade comunitária na Vila Santa Marta. Durante todo o período em que os estudantes e professores da Universidade de Michigan estiveram na Vila Santa Marta, o trabalho foi realizado com o auxílio da escola, da COM-VIDA, da Associação de Moradores, Prefeitura Municipal, Organizações Religiosas, Movimento Bairro Melhor e comunidade em geral.

\section{Metodologia}

Múltiplos foram os métodos utilizados para a coleta de dados em um curto espaço de tempo (quinze dias). Eles foram fundamentados em conceitos básicos e técnicas de avaliação rápida, o que possibilitou a compreensão preliminar e qualitativa das situações encontradas.

As técnicas de avaliação rápida foram fundamentadas em três conceitos básicos: perspectiva sistêmica, triangulação de coleta de dados e coleta e análise de dados interativos (BEEBE, 1995). Os conceitos básicos e suas técnicas de pesquisa possibilitaram uma abordagem flexível, mas rigorosa, para a coleta e análise de dados pelas equipes envolvidas na recolha de dados, sendo estas de diferentes origens. Entre os métodos utilizados estavam:

- $\quad$ Entrevista com moradores e agentes da prefeitura municipal com a finalidade de entender os problemas levantados pela comunidade Santa Marta. As entrevistas duraram entre vinte minutos a uma hora. Foram conduzidas em português e traduzidas simultaneamente para o inglês por supervisores falantes do português. As questões não foram limitadas, pois foi permitido que cada entrevistado(a) discutisse pontos importantes para além do que foi perguntado. Foram entrevistados(as) integrantes de oito secretarias municipais diferentes - dentre elas, a Secretaria do Meio Ambiente, Secretaria de Gestão e Governo, Serviço Social de Habitação, Secretaria de Obras Públicas, Secretaria de Educação, Secretaria de Orçamento Participativo -, e cinco membros da comunidade Santa Marta. Cada entrevista foi liderada por um membro da equipe da Universidade de Michigan com a ajuda de um tradutor, sendo gravada para tradução e transcrição posterior.

- Grupos Focais realizados com alunos e alunas da Educação de Jovens e Adultos da EMEF Santa Marta. Por meio da organização de grupos de discussão informal e de tamanho reduzido, o propósito foi o de obter informações de caráter qualitativo em

Argumentos Pró-Educação, Pouso Alegre, v. 4, n. 12, p. 1288- 1304. set. - dez., 2019 
profundidade. Essa técnica é geralmente utilizada por ser rápida e de baixo custo para avaliação, assim como proporciona a obtenção de dados, informações qualitativas e uma grande riqueza de informações (USAID, 1994). Foi uma oportunidade para triangular dados e confirmar informações que haviam sido recolhidas por meio dos outros métodos de pesquisa. Foram organizados três grupos focais para discussão sobre a comunidade, o despejo de lixo e entulho e os espaços de lazer. Os(as) líderes e tradutores(as) do grupo iniciavam as discussões com certas questões abertas a respeito dos três tópicos gerais. Os(as) líderes dos grupos tomavam notas com base nas traduções. Cada encontro contou com vinte a trinta participantes e teve duração de aproximadamente uma hora. Também foram gravadas as discussões para escuta e futuras traduções.

- $\quad$ Pesquisa Domiciliar com o objetivo de coletar dados sobre a gestão do lixo, recreação e lazer, percepções sobre a comunidade, percepções ambientais e demografia. O questionário incluiu vinte questões de múltipla escolha, conforme escala Likert $^{9}$, e uma questão aberta. Os questionários foram aplicados a cada quatro casas do lado esquerdo de cada rua. Esse método permitiu que os resultados - e, por conseguinte, as recomendações abrangessem todas as partes da Vila Santa Marta, assim como o Loteamento Tancredo Neves ${ }^{10}$.

- Caminhada Transversal com o intuito de identificar locais de interesse especiais. "A Caminhada Transversal consiste em percorrer uma determinada área, acompanhado de informantes locais e que conheçam bem a região" (SOUZA, 2009 p. 43). Esse exercício resultou no registro das condições construídas, ambientais e sociais encontradas ao longo do caminho. Após a caminhada foi realizado um encontro para que os participantes comparassem suas impressões, refletissem e construíssem um entendimento comum, assim

$9 \mathrm{Na}$ escala Likert, o entrevistado responde por meio de um critério que pode ser objetivo ou subjetivo. O que se busca é medir o nível de concordância ou discordância a uma afirmação. Frequentemente, são usadas cinco opções de respostas. O formato típico de um item Likert é: discordo totalmente, discordo parcialmente, indiferente, concordo parcialmente, concordo totalmente. Para mais informações, sugere-se DALMORO e VIEIRA (2013).

10 Loteamento localizado ao lado da Vila Santa Marta da qual a EMEF Santa Marta faz parte.

Argumentos Pró-Educação, Pouso Alegre, v. 4, n. 12, p. 1288- 1304. set. - dez., 2019

ISSN: 2448-2803 http://dx.doi.org/10.24280/ape.v4i12.467 
como possibilitou espaço para levantamento de algumas soluções para as questões notadas durante a caminhada (CATALYTIC COMMUNITIES, 2015). Um grupo de estudantes da Universidade de Michigan e da COM-VIDA acompanhou os moradores nas duas rotas préestabelecidas. Em um mapa, com as ruas da Vila Santa Marta e Loteamento Tancredo Neves, foram marcados os locais que mais gostavam de frequentar, as áreas em que identificavam mais lixo e as áreas pelas quais evitavam passar.

- Planilha do Caminho para Casa desenvolvida pelos professores e estudantes da Universidade de Michigan para identificar quais eram os locais mais relevantes da comunidade para os(as) moradores(as) crianças. Foi pedido para alguns alunos(as) da EMEF Santa Marta que mapeassem seu trajeto até sua casa. A planilha foi implementada com ajuda de uma professora de Geografia da escola que incluiu esta atividade em suas aulas. Participaram dessa atividade 101 estudantes.

- Mapeamento da Comunidade em Sala de Aula realizado com grupos de quatro a seis estudantes em três salas de aula, produzindo 14 mapas feitos com a participação dos alunos. Cada grupo de alunos recebeu um mapa aéreo da Vila Santa Marta e adesivos para marcarem suas respostas a questões específicas. Os integrantes da Com-Vida receberam treinamento para aplicar essa atividade. Foi pedido para os(as) alunos(as) que localizassem suas casas no mapa para poderem se orientar. Em seguida, cada grupo trabalhou com uma série de perguntas feitas pelos facilitadores da Com-Vida e foram marcando suas respostas nos mapas aéreos:

1) Quais são seus lugares preferidos para brincar ou se socializar?

2) Que pontos de referência você vê na sua vizinhança?

3) Onde você obtém alimento?

4) Onde você se encontra com seus amigos?

5) Há áreas que você evita? Onde?

6) Onde você vê muito lixo?

7) Onde fica o arroio?

8) Poderia desenhá-lo no mapa?

Os facilitadores disponibilizaram aos estudantes quatro pedaços de papéis em cores distintas que representavam diferentes itens. Eles deveriam decidir, enquanto um 
grupo, onde colocar cada item no mapa da Santa Marta, dentre eles um parque, um campo esportivo, um conjunto de bancos, uma loja.

- Mapeamento Comunitário Interativo $(\mathrm{MCl})$ que procurou incentivar todos os(as) envolvidos(as) no projeto a contribuir com seu conhecimento espacial e local, assim como com a produção de dados necessários para localizar a comunidade Santa Marta no mapa (SHKABATUR, 2014). Ao realizar o $\mathrm{MCl}$, foi priorizado o descarte indevido de resíduos, espaço público e pontos de lazer. Essa metodologia pode assumir diferentes formas, inclusive priorizando mapas desenhados à mão, representando mapas mentais (SLETTO, 2009) e o uso de mapas aéreos, permitindo que os participantes identificassem alguns locais com maior especificidade (THE JANE GOODALL INSTITUTE, 2013). Para coletar informações na comunidade Santa Marta de modo mais amplo foi realizado um segundo exercício de mapeamento da comunidade, aberto a todos(as) os(as) moradores(as). Durante as entrevistas foram convidados(as) membros da comunidade para uma palestra informativa sobre o projeto. Após a palestra, foi solicitado que os(as) moradores(as) contribuíssem opinando sobre o que poderia ajudar a Vila Santa Marta em relação aos seus problemas socioambientais. Foram disponibilizados cinco mapas aéreos grandes nas paredes da Associação de Moradores. Cada um continha uma questão e os(as) participantes utilizaram adesivos para inserir suas respostas no mapa. Os(as) professores(as) e estudantes da ComVida ficaram à disposição para ajudar os membros da comunidade a se orientarem no mapa e a responderem adequadamente as questões.

Além dos mapas disponibilizados durante o $\mathrm{MCl}$, também foram incluídos quatro quadros de opinião na comunidade que traziam as seguintes questões: "O que você gosta na sua comunidade?" e "O que você gostaria de ver na sua comunidade?". Os quadros foram instalados na EMEF Santa Marta e os outros três em paredes externas de mercados locais. Para garantir que o analfabetismo não fosse um obstáculo à participação, estudantes da ComVida ajudaram no registro das respostas dos participantes

\section{Resultados e discussões}

A partir da parceria, os(as) estudantes e os(as) professores(as) da Universidade de Michigan produziram coletivamente, como resultado da pesquisa, um documento 
denominado Together We Make Santa Marta Home - Juntos Fazemos de Santa Marta a Nossa Casa (UM, 2015) com recomendações específicas para a melhoria da qualidade de vida dos moradores da Vila Santa Marta. Nesse documento foram sugeridas algumas ações para a escola e comunidade, fundamentadas no contexto social local e refletiram as prioridades e aspirações dos(as) moradores(as). Dentre elas: dissuadir o despejo indevido de resíduos, estimular o orgulho e a visibilidade da comunidade, melhorar a segurança, controlar as inundações, melhorar as ruas, redes de esgoto e infraestrutura da Vila Santa Marta.

Após a conclusão do projeto, o documento (produto final) foi encaminhado para alguns concursos e recebeu dois prêmios internacionais ${ }^{11}$. Com base em sua avaliação inicial, das necessidades da comunidade, a equipe da Universidade de Michigan retornou para a EMEF Santa Marta para apresentar e implementar as seguintes recomendações:

- Projetar soluções para o espaço físico, dando prioridade para a entrada da comunidade, a drenagem de águas pluviais através de jardins de chuva e recreação em quadra poliesportiva.

- Mapear a comunidade com o auxílio de um aplicativo no qual são coletados dados locais, contribuindo para o reconhecimento, localização e ensino de novas habilidades tecnológicas.

- Oferta de acesso à internet. A ideia foi instalar roteadores na comunidade tendo na escola o ponto de acesso inicial para a internet

\section{Implementação das Recomendações}

Com as verbas recebidas (prêmios), foi possível contemplar algumas das recomendações citadas anteriormente. Para a implementação das recomendações foi realizado um novo Mapeamento Comunitário Interativo - MCI (SHKABATUR, 2014), porém com outro formato, pois contou com a utilização de tablets nos quais foi instalado um aplicativo que possibilitou o mapeamento e levantamento de dados locais a partir de questionário. "As iniciativas de $\mathrm{MCl}$ podem assumir diversas formas, mas as metas do

11 Disponível em: https://news.umich.edu/pt-br/maos-a-obra-em-comunidade-carente-do-sul-do-brasil/. Acesso em: 20 ago. 2018. 
programa focam o processo de Mapeamento Participativo, que pode promover a agência comunitária e facilitar um diálogo mais claro entre líderes municipais, provedores de serviços e moradores das comunidades." (UM, 2015, p. 123; tradução da autora). De acordo com Linhares e Santos (2017, p. 56), com base nos estudos de Nelson e Wright (1995),

o mapeamento participativo é o registro de conhecimentos advindos de um grupo específico em relação ao ambiente vivido, sendo colocado em prática com a ajuda de instrumentos tecnológicos como imagens de satélites, cartas e mapas. A busca por ações mais eficientes de conservação pode ser realizada mediante a utilização do mapeamento participativo. Deve-se associar os conhecimentos locais das pessoas sobre seu espaço de vivência, informações relacionadas à complexidade dos ecossistemas, assim como incluir as necessidades locais nos projetos de gestão da biodiversidade.

Especificamente no projeto Together We Make Santa Marta Home, o objetivo da ação foi o de habilitar membros da comunidade para mapearem e pesquisarem os locais que constituem sua comunidade. Além desse objetivo, o $\mathrm{MCl}$ possibilitou o aprendizado de novas habilidades, construiu e fortaleceu a identidade da comunidade, estabeleceu o diálogo direto entre a comunidade e a administração pública local.

Segundo Ana Paula Pimentel (COMITIVA DA UNIVERSIDADE DE MICHIGAN RETORNA À VILA SANTA MARTA, 2016), professora coordenadora do projeto, em entrevista cedida para a Prefeitura de São Leopoldo, os "locais carentes não mantêm a mesma estrutura, ao longo do tempo vão surgindo invasões e ruas que não aparecem no planejamento urbano. 0 mapeamento é essencial para as próximas ações" ${ }^{12}$.

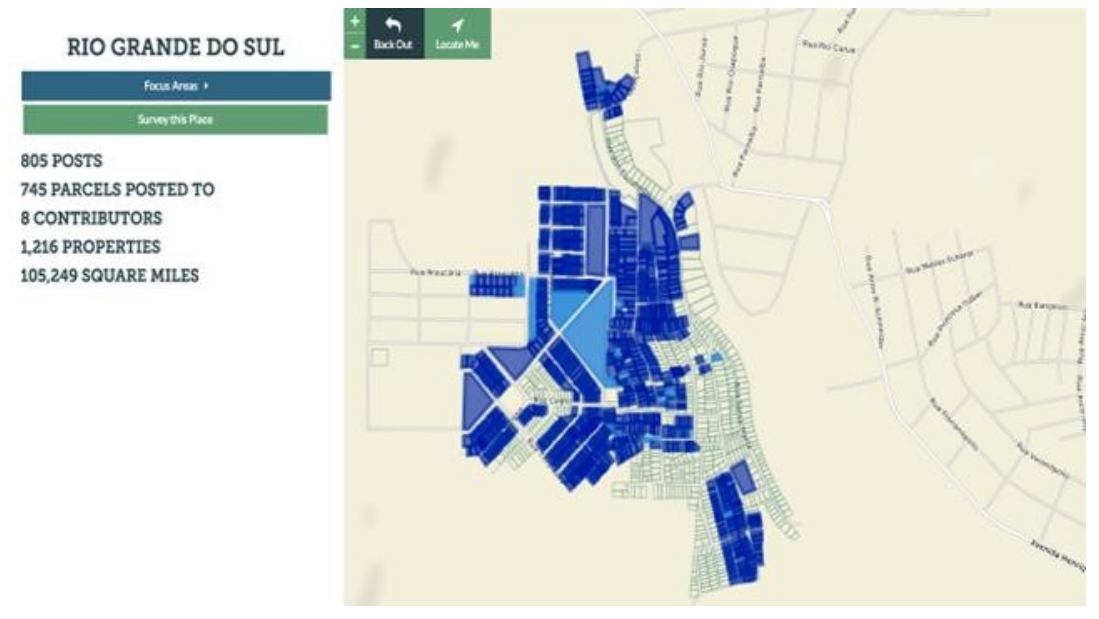

12 Disponível em: http://radionovaprogresso.com.br/comitiva-da-universidade-de-michigan-retorna-a-vila-santamarta/. Acesso em 25 jul. 2018.

Argumentos Pró-Educação, Pouso Alegre, v. 4, n. 12, p. 1288- 1304. set. - dez., 2019

ISSN: 2448-2803 http://dx.doi.org/10.24280/ape.v4i12.467 
Figura 1- Aplicativo. Em azul, lotes visitados. Fonte: Loveland Technologies.

Ao conhecer o local e suas prioridades, foi possível verificar quais os desejos da comunidade, assim como (re)planejar as ações de melhorias. Outro material essencial foi o mapa físico da Vila Santa Marta, que foi utilizado como instrumento para a releitura e interpretação da realidade. Por meio dele foi possível repensar, replanejar e reorganizar o projeto Together We Make Santa Marta Home juntamente com os(as) estudantes da EMEF Santa Marta, os(as) professores(as) e comunidade

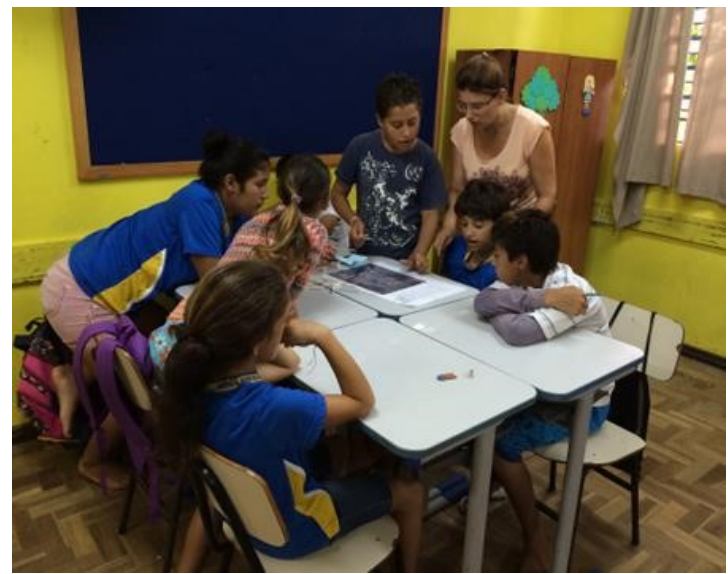

Figura 2 - MIC em sala de aula.

Fonte: FORD BLUE OVAL NETWORK (2018)

Um dos desdobramentos do $\mathrm{MCl}$ e do uso do mapa físico local foi a construção de um jardim de chuva que teve como objetivo minimizar inundações, problemas de poluição ambiental e embelezar o espaço público. Os ecossistemas naturais de um jardim de chuva trazem diversos benefícios para a comunidade. A Vila Santa Marta é cortada pelo Arroio da Manteiga e possui diversas áreas úmidas que precisam ser preservadas. O jardim de chuva contribui

para aumentar a beleza paisagística da rua; reduz parte do volume do escoamento superficial; é eficiente na remoção de sedimentos finos, metais, nutrientes e bactérias; possibilita grande flexibilidade de desenho de projetos; reduz o tamanho e custo do sistema de drenagem de jusante; reduz inundações na bacia e melhora a qualidade das águas (SOLUÇÕES PARA CIDADES, 2013).

O local escolhido para a construção do jardim de chuva foi o que mais apresentava ocorrência de inundações, assim como possuía uma nascente, localizado na rua principal da Vila Santa Marta. 


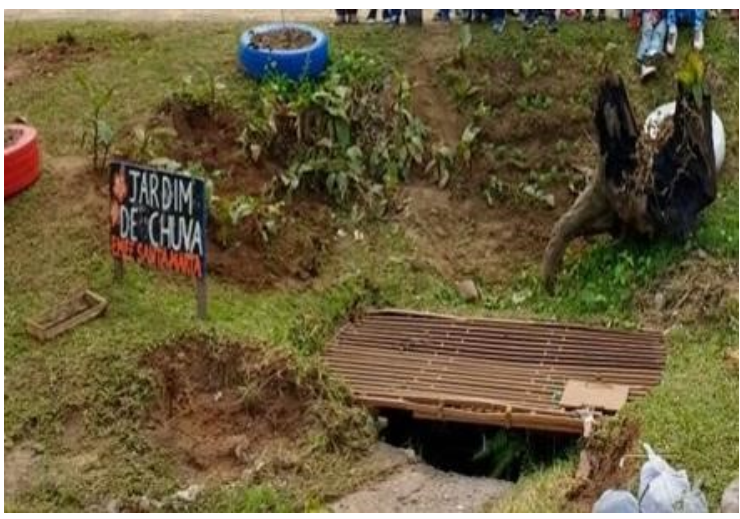

Figura 3 - Construção de Jardim de Chuva.

Fonte: EMEF Santa Marta

Esse jardim, após sua construção, passou a ser cuidado por moradores (as) da Vila Santa Marta. A entrada da comunidade foi apontada no mapa como uma das prioridades. Após os estudos realizados foi percebido que não havia identificação física da Vila Santa Marta em nenhum lugar. Com o objetivo de aumentar a visibilidade pública da comunidade, o senso de pertencimento, identidade e compreensão do lugar,foi instalada uma placa na entrada da Vila Santa Marta.

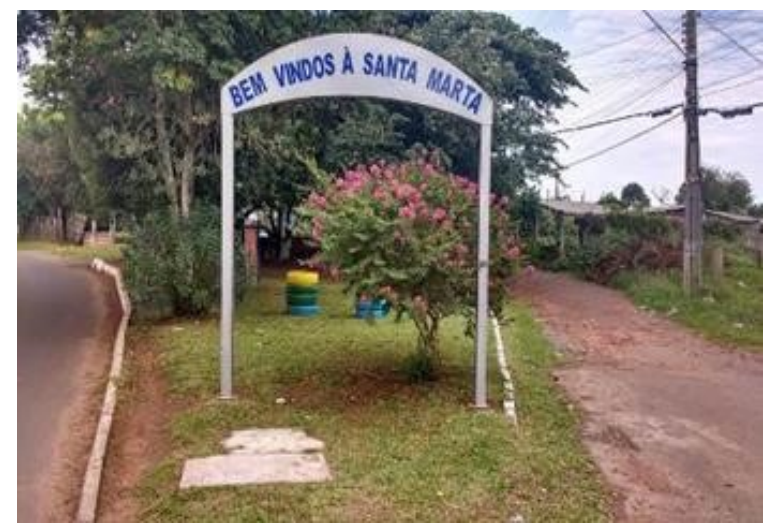

Figura 4 - Instalação de (2017).

Foto: Dilce Rosa.

Outra recomendação implementada foi a construção da Quadra Comunitária Poliesportiva Santa Marta. Uma das prioridades destacadas pela comunidade, durante as entrevistas, foi a construção de um espaço de lazer. Até então a EMEF Santa Marta era o único espaço aberto, nos finais de semana, para o lazer. Em entrevista cedida no dia da inauguração da quadra, para um jornal local da comunidade, a presidente da Associação de Moradores da Vila Santa Marta ressaltou: "o desejo de nossa vila é ser vida" (ENFOQUE SANTA MARTA, 2017, p. 4). Esse posicionamento vai ao encontro do que é entendido por comunidade/sociedade 
sustentável na EMEF Santa Marta. De acordo com Brandão (2005, p. 87),

Como um princípio de Vida oposto à ideia de um crescimento econômico ilimitado, uma sociedade sustentável é a que busca mudanças e transformações que satisfaçam as verdadeiras vocações e necessidades dos seres humanos, pois uma das inovações da sociedade sustentável é a sua abertura ao futuro. É a consciência de que somos corresponsáveis por nós em nosso tempo e, também, pela qualidade de Vida e pela integridade da Natureza do Mundo das gerações futuras.

Com a construção da quadra poliesportiva, muitas foram as mudanças e entendimento em relação à utilização do espaço comunitário. Antes, por muitas vezes utilizado para a drogadição, o espaço onde foi construída a quadra ganhou outro sentido, satisfazendo as necessidades da comunidade. Escola de futebol infantil, atividades físicas e capoeira passaram a fazer parte do cotidiano da Vila Santa Marta.

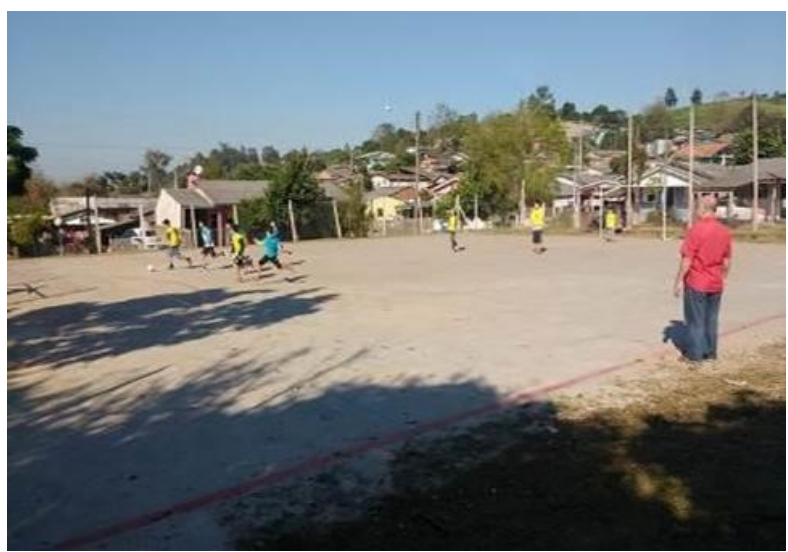

Figuras 5 - Atividades na quadra poliesportiva.

Fonte: Dilce Rosa.

Após as implementações realizadas, outros desdobramentos ocorreram. A EMEF Santa Marta e a comunidade continuaram buscando por melhorias. Participaram de outros concursos nos quais foram premiadas, assim como buscaram ampliar as parcerias por meio do Movimento Bairro Melhor. Por meio do engajamento de todos(as) os(as) envolvidos(as) e de ações sensibilizadoras, foi possível que outros conhecimentos e entendimentos ocorressem. Outros valores, habilidades, atitudes e competências passaram a fazer parte das vidas dos(as) moradores(as) da Vila Santa Marta (BRANDÃO, 2005).

Um exemplo foi a Associação de Moradores que, com o auxílio de artistas locais, foi revitalizada por meio da Arte do Grafite, passando a ter visibilidade. De acordo com Campos 
(2009, p. 37; grifo do autor), a partir das contribuições de Andrea Brighenti (2007), "a dimensão relacional que se estabelece e as assimetrias que a visibilidade prevê, revelando distintas condições sociais, sugerem que este campo se pode converter num terreno para o desenvolvimento de estratégias". Nesse sentido, a estratégia da Associação de Moradores foi a de tornar o espaço percebido e entendido como um lugar para todos(as) e de todos(as), um lugar de tomada de decisões, de ideias, de arte e de encontros.

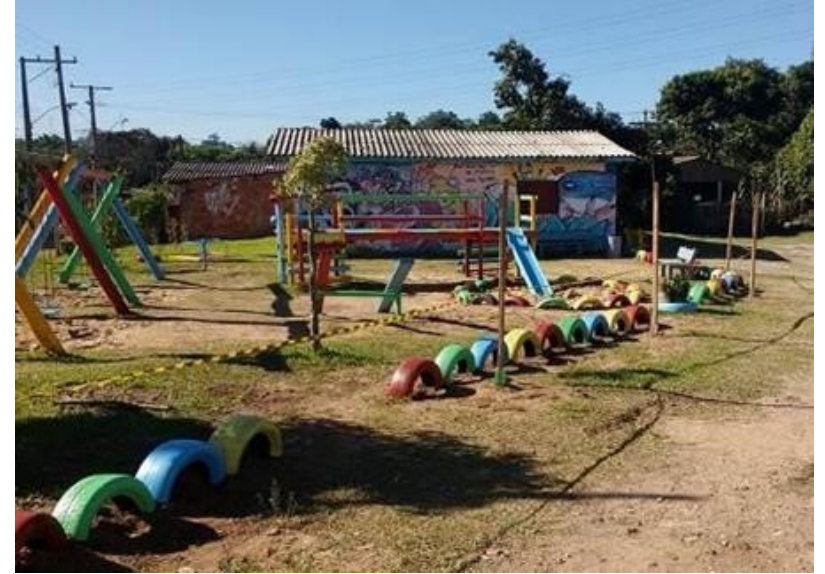

Figura 6 - Revitalização da Associação de Moradores.

Foto: Dilce Rosa.

As novas tecnologias, principalmente o acesso à internet, também passaram a estar presentes no dia-a-dia dos(as) alunos(as) e moradores(as) da EMEF Santa Marta. A ideia foi a de criar redes comunitárias autônomas, como os exemplos bem-sucedidos de países como a Espanha, a Alemanha e a Índia. "Essas redes possibilitam a criação de serviços locais (sites, rádio, compartilhamento de arquivos), além de possibilitarem autonomia política, tecnológica e de comunicações" (MICHIGAN NEWS, 2016). O laboratório de informática da escola passou a ser aberto aos moradores(as), assim como a utilização de notebooks, tablets e máquina fotográfica foi disponibilizada para os(as) alunos(as) sempre que necessário.

Argumentos Pró-Educação, Pouso Alegre, v. 4, n. 12, p. 1288- 1304. set. - dez., 2019 ISSN: 2448-2803 http://dx.doi.org/10.24280/ape.v4i12.467 


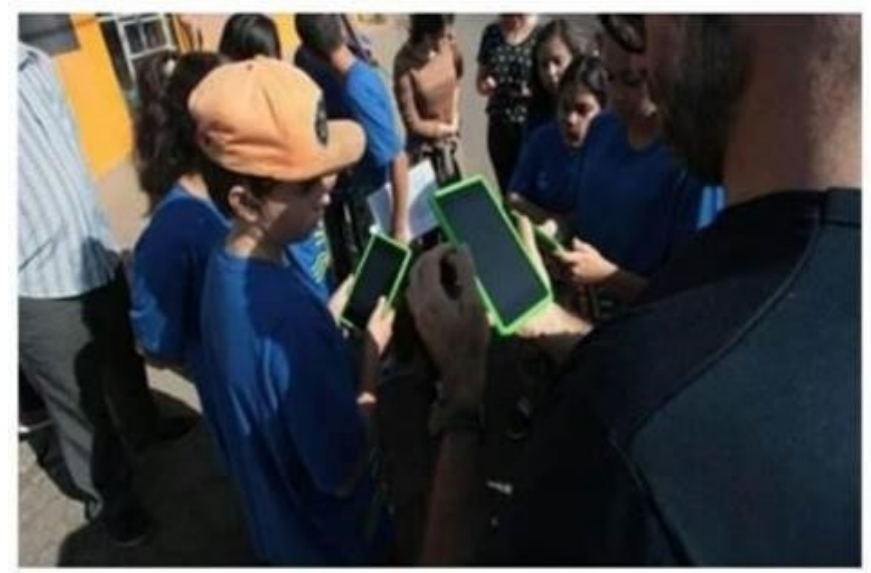

Figura 7 - Utilização de novas tecnologias.

Fonte: Jornal VS.

Os projetos desenvolvidos pela COM-VIDA tiveram continuidade. Foram fortalecidos e ampliados por meio de saídas de campo, visitas às casas dos(as) moradores(as), entrega de informativos, pesquisas, intervenções com/na comunidade, participação em eventos locais e regionais, entre outras ações.

\section{Considerações finais}

As experiências vivenciadas na EMEF Santa Marta partiram de um projeto de ação denominado "Água Viva", construído a partir das políticas de educação para a sustentabilidade, principalmente as fomentadas pela IV CNIJMA. As conferências foram fundamentais no sentido de pensar e refletir coletivamente sobre a realidade da escola e comunidade.

As parcerias possibilitaram que o projeto atingisse seu objetivo inicial, o de "sensibilizar a comunidade local para os perigos e consequências de se conviver próximo aos locais com água contaminada e poluída, assim como alertar para a responsabilidade que cada um tem com o arroio e o lugar onde vivem" (GROHE, 2015), assim como contribuíram para que ele fosse além. Um exemplo foi a criação do Movimento Bairro Melhor, assim como o envolvimento significativo na construção e implementação do projeto "Together We Make Santa Marta Home", ultrapassando fronteiras e firmando parcerias.

A universidade de Michigan, conforme o relatado, com a organização metodológica utilizada, promoveu diálogos entre os conhecimentos científicos, culturais e saberes locais, dando atenção às necessidades encontradas. Cada pesquisador(a) envolvido(a), tanto

Argumentos Pró-Educação, Pouso Alegre, v. 4, n. 12, p. 1288- 1304. set. - dez., 2019

ISSN: 2448-2803 http://dx.doi.org/10.24280/ape.v4i12.467 
integrantes da COM-VIDA, quanto alunos(as) da Universidade de Michigan, oriundos(as) de distintas realidades, áreas de conhecimentos e idiomas, realizaram as coletas de dados sem que as diferenças fossem um empecilho para a realização do projeto. A realização da coleta de dados e as outras atividades foram realizadas durante quinze dias e contou com o envolvimento efetivo de aproximadamente trinta pessoas. Embora realizado em curto espaço de tempo, o envolvimento foi intenso e profundo. Provocou trocas afetivas entre as pessoas e o lugar, tanto que o contato entre a Universidade de Michigan, EMEF Santa Marta e comunidade local continuam, mesmo à distância.

As ações realizadas foram provocadoras de mudanças significativas tanto de comportamentos como de atitudes de todos(as) os(as) envolvidos(as). Conhecer o local onde se vive, a partir de outros olhares e perspectivas, fez com que os(as) moradores(as) da Vila Santa Marta se reconhecessem como sujeitos capazes de recriar e transformar seu espaço.

As vivências e projetos desenvolvidos na/pela EMEF Santa Marta poderão servir de exemplo para outras escolas, universidades, comunidades e municípios, com objetivos que contemplem os problemas socioambientais de cada realidade, partindo de políticas públicas, de ações conjuntas, do protagonismo ambiental, do ensino, da pesquisa e da extensão. Como vimos, as ações são possíveis a partir do engajamento de pessoas e o envolvimento de diversos seguimentos em prol de um mesmo bem comum: a educação para sustentabilidade.

\section{Referências}

BEEBE, J. Basic concepts and techniques of rapid appraisal. Human organization, v. 54, n. 1. p. 42-51.

BRANDÃO, C. R. Aqui é onde eu moro, aqui nós vivemos: escritos para conhecer, pensar e praticar o Município Educador Sustentável. 2. ed. Brasília: MMA, Programa Nacional de Educação Ambiental, 2005.

BRASIL. Ministério da Educação, Secretaria de Educação Continuada, Alfabetização, Diversidade e Inclusão, Ministério do Meio Ambiente. Vamos cuidar do Brasil com escolas sustentáveis: educando-nos para pensar e agir em tempos de mudanças socioambientais globais. Brasília: A Secretaria, 2012.

BRIGHENTI, A. Visibility: a category for the social sciences. Current Sociology, v. 5, p. 323342, 2007.

CAMPOS, R. M. O. "All City" - Graffiti Europeu como modo de comunicação e transgressão no espaço urbano. Revista de Antropologia, São Paulo, v. 52, n. 1, p. 11-46, jan./jun. 2009.

Argumentos Pró-Educação, Pouso Alegre, v. 4, n. 12, p. 1288- 1304. set. - dez., 2019

ISSN: 2448-2803 http://dx.doi.org/10.24280/ape.v4i12.467 
CATALYTIC COMMUNITIES. 2015. Community Mapping Through Transect Walks. Disponível em: http://catcomm.org/transect-walk/. Acesso em: 26 jul. 2018.

COMITIVA da Universidade de Michigan retorna à Vila Santa Marta. Rádio Nova Progresso. São Leopoldo, RS, 06 maio 2016. Disponível em:

http://radionovaprogresso.com.br/comitiva-da-universidade-de-michigan-retorna-a-vilasanta-marta/. Acesso em: 25 jul. 2018.

DALMORO, M.; VIEIRA, K. M. Dilemas na construção de escalas tipo Likert: o número de itens e a disposição influenciam nos resultados? Revista Gestão Organizacional, v. 6, n. 3, p. 161174, 2013. Disponível em:

https://bell.unochapeco.edu.br/revistas/index.php/rgo/article/view/1386. Acesso em: 26 jul. 2018.

ENFOQUE SANTA MARTA. Quadra poliesportiva inaugurada. Jornal experimental produzido por alunos do Curso de Jornalismo da Unisinos São Leopoldo (RS). mar./abr. 2017. Disponível em: https://issuu.com/unisinosagexcom/docs/enfoque_sm_1. Acesso em: $01 \mathrm{fev}$. 2018.

FORD BLUE OVAL NETWORK. Together We Make Santa Marta Home: Fostering Community Ownership and Environmental Stewardship in Vila Santa Marta, Brazil. 2018. Disponível em: https://www.fordblueovalnetwork.org/together-we-make-santa-marta-home-fosteringcommunity-ownership-and-environmental-stewardship-vila. Acesso em: 25 jul. 2018.

FÓRUM INTERNACIONAL DE ORGANIZAÇÕES NÃO-GOVERNAMENTAIS E MOVIMENTOS SOCIAIS. Tratado de Educação Ambiental para sociedades sustentáveis e responsabilidade global. In: TRATADO das ONGs; aprovado no Fórum Internacional de Organizações NãoGovernamentais e Movimentos Sociais, no Âmbito do Fórum Global - ECO-92. Rio de Janeiro: Eco, 1992, p. 193-196.

GROHE, S. L. S. Escolas sustentáveis: três experiências no município de São Leopoldo - RS. 2015. 136 f. Dissertação (Mestrado em Educação) - Faculdade de Educação, Pontifícia Universidade Católica do Rio Grande do Sul, Porto Alegre, 2015.

HENRIQUES, R. et al. (org.). Educação ambiental: aprendizes de sustentabilidade. Brasília: Secad/MEC, 2007.

LINHARES, T. S.; SANTOS, L. F. U. Mapeamento Participativo: subsídio à gestão participativa e ao manejo sustentável de recursos naturais de comunidades tradicionais. Sociedade e Território, Natal, v. 29, n. 1, p. 50-70, jan./jun. 2017.

MEC. IV Conferência Nacional Infantojuvenil pelo Meio Ambiente. 2013. Disponível em: http://conferenciainfanto.mec.gov.br/. Acesso em: 06 fev. 2018.

MICHIGAN NEWS. Mãos à obra em comunidade carente do sul do Brasil. University of Michigan. 2016. Disponível em: https://news.umich.edu/pt-br/maos-a-obra-emcomunidade-carente-do-sul-do-brasil/. Acesso em: 16 mar. 2019.

NELSON, N.; WRIGHT, S. Participation and power. In: NELSON, N.; WRIGHT, S. Power and participatory development. Theory and practice. London: Ed. Intermediate Tachnology Publications, 1995.

Argumentos Pró-Educação, Pouso Alegre, v. 4, n. 12, p. 1288- 1304. set. - dez., 2019

ISSN: 2448-2803 http://dx.doi.org/10.24280/ape.v4i12.467 